\title{
No evidence for a correlation of Glutathione S-Transferase polymorphisms and chronic rhinosinusitis*
}

\author{
Kai Fruth ${ }^{1}$, Nicole Best ${ }^{1}$, Mohammad Amroํ, Katharina Ingel ${ }^{2}$, Jan Gosepath ${ }^{1}$, \\ Wolf J. Mann ${ }^{1}$, Juergen Brieger ${ }^{1}$ \\ 1 Department of Otolaryngology, Head and Neck Surgery, University Medical Center of the Johannes Guten- \\ berg University Mainz, Germany \\ 2 Institute of Medical Biostatistics, Epidemiology and Informatics (IMBEI) at the University Medical Center of \\ the Johannes-Gutenberg-University Mainz, Germany
}

\begin{tabular}{|l}
\hline SUMMARY \\
Objective: Cellular detoxification mechanisms are mandatory for cellular protection against oxida- \\
tive stress and reactive oxygen species. One major group of antioxidative active enzymes involved in \\
cellular detoxification are the Glutathione S-Transferases (GST). Multiple subtypes like GSTM1, \\
GSTP1, and GSTT1 and variants of them are known, arising from allelic variations of the GST \\
loci. Moreover, functional variants occur in high percentages and have been associated with diseases \\
like bronchial asthma and bronchial hyperresponsiveness. The interplay of oxidative stress, detoxi- \\
fying genes like GSTs and the genesis of respiratory tract illness is under contradictory debate. In \\
this study, we analysed the potential association of GST-polymorphisms and chronic rhinosinusitis \\
(CRS). \\
Methods: In total 170 nasal tissue samples, 49 tissue samples from patients with CRS without nasal \\
polyps, 69 tissue samples from CRS with nasal polyps and 52 healthy tissue controls of the infe- \\
rior turbinate were analysed for their individual GST-status. Genotypes for GSTM1 (null versus \\
present), GSTT1 (null versus present), and GSTP1 (Ile105Val) were determined by Polymerase \\
Chain Reaction. The respective genotypes were correlated to the incidence of CRS with and without \\
nasal polyps in aspirin-tolerant and intolerant patients and to the individual health status concern- \\
ing asthma and allergies. \\
Results: No correlation between any GST-polymorphism and CRS with and without nasal polyps \\
or allergies or asthma or aspirin-intolerance was observed. \\
Conclusion: Our results do not suggest that there is a relevant genetic predisposition considering the \\
individual GST-status for the susceptibility of nasal respiratory epithelia leading to CRS. \\
Key words: Glutathione S-transferases, polymorphisms, chronic rhinosinusitis, oxidative stress, \\
asthma
\end{tabular}

\section{INTRODUCTION}

The interest in genetic diversity contributing to the individual susceptibility to environmental distress and airway diseases has emerged in recent years. Future advances in the management of upper airway diseases are likely to be influenced by a better understanding of genetic variations interfering with exogenous triggers and their relation to individual disease severity. Glutathione S-Transferase (GST) isoenzymes play a critical role in cellular metabolism by detoxification of oxidized and corrupted molecules ${ }^{(1)}$. The biologic activity of the respective polymorphisms appears to provide the basis for inter-individual differences in detoxification capacity. Functional variants of the different isoforms of GST (GSTP1, GSTM1, GSTT1) occur frequently and their contribution to the onset of respiratory diseases is under discussion ${ }^{(2,3)}$
For the lower airways, extensive work has been dedicated to explore the relation of expressed candidate genes and the risk of bronchial hyperresponsiveness (BHR) and asthma with contradictory findings ${ }^{(2,4-10)}$. Fryer et al. reported an association of GST-polymorphisms and the incidence and severity of both, BHR and asthma (7). Additionally, Feuillet-Fieux postulated a potential role of GST activity and genotype in modulating Pseudomonas aeruginosa lung infection in cystic fibrosis patients ${ }^{(11)}$. Others have described an influence of GSTP1 gene polymorphisms on the effect of antenatal steroids on the newborn lung ${ }^{(12)}$. More recent publications have eluded striking histopathological similarities between chronic rhinosinusitis (CRS) ${ }^{(13)}$ and bronchial asthma, suggesting common pathways in their etiology ${ }^{(14)}$. However, little is known on 
the significance of GST-polymorphisms in the pathogenesis of inflammatory diseases of the upper airways. Gilliland reported an association of GSTP1 with the risk and severity of acute respiratory infections ${ }^{(3)}$. Others found a 2-fold increased risk of nasal polyps in individuals with the GSTT1-null genotype suggesting the involvement of GST-polymorphisms in chronic inflammatory diseases as well ${ }^{(15)}$. In another study performed by Arbag et al. analysing GSTM1 and GSTT1 only the combined GSTM1-null/GSTT1-null genotype occurred more frequently in nasal polyps ${ }^{(16)}$. To shed more light on these few and inconclusive data concerning the individual GST-status and the development of inflammatory diseases of the upper respiratory tract, we performed a detailed study investigating the GSTM1, -T1, and -P1 polymorphisms in sinunasal mucosal samples obtained from patients with CRS without and with nasal polyps and in nasal mucosal samples obtained from the inferior turbinate from patients without CRS.

\section{PATIENTS AND METHODS}

\section{Patients}

In total, 170 consecutive patients (114 men, 56 female, mean age 42 years) operated between May 2006 and January 2008 at the ENT-department of the University Medical Center of the Johannes Gutenberg University Mainz were included in this study. Tissue samples from normal inferior turbinate $(\mathrm{n}=$ 52) were obtained from patients subjected for surgery because of nasal breathing impairment (turbinate reduction). One hundred and eighteen sinunasal samples were collected from patients operated because of chronic rhinosinusitis: 49 without nasal polyps (CRSNP-) and 69 with nasal polyps $\left(\mathrm{CRSNP}^{+}\right)$. CRS was diagnosed by nasal endoscopy and by computer tomography ${ }^{(13)}$. Sixtyfour of these patients were suffering from allergies, diagnosed by prick test or radioallergosorbent test, 27 from asthma and 28 from aspirin-intolerance. Asthma and aspirin-intolerance were clinically diagnosed by patients' history. The samples were immediately used for DNA-isolation or snap frozen in liquid nitrogen and stored at $-80^{\circ} \mathrm{C}$ until analysis of GST-subtypes and -polymorphisms.

\section{DNA isolation}

For DNA-isolation, the DNeasy Tissue Kit from Qiagen (Hilden, Germany) was used according to the manufacturer's instructions. In brief, tissue was minced in liquid nitrogen and digested using Proteinase K. After several washings and centrifugation steps using special columns, the chromosomal DNA was eluted and stored at $-20^{\circ} \mathrm{C}$ until PCR-analysis.

\section{PCR analysis of GST-subtypes and -polymorphisms}

Concentrations of the isolated DNA-samples were defined by OD260/280 measurement and adjusted to $20 \mathrm{ng} / \mu \mathrm{l}$. GSTsubtypes $-\mathrm{M}$ and $-\mathrm{T}$ were analysed by Q-PCR using subtype-specific primers and probes. GST-P1-polymorphisms were analysed by P-specific primers and polymorphisms were discriminated by specific probes (Table 1); sequences have been published before ${ }^{(3)}$. PCRs were performed in duplicate for each primer set. We used the Taq-Man ${ }^{\mathrm{TM}}-\mathrm{PCR}$ tech- nology (GeneAmp ${ }^{\circledR} 700$ Sequence Detection System, ABI, Weiterstadt, Germany). PCRs were performed using $100 \mathrm{ng}$ of each DNA-sample for amplification. After addition of $1.75 \mu \mathrm{l}$ of each primer $(5 \mu \mathrm{M}), 1.75 \mu \mathrm{l}$ probe $(2 \mu \mathrm{M})$, and $5.25 \mu 1 \mathrm{H}_{2} \mathrm{O}$ to $17.5 \mu$ l Mastermix (ABI) PCR was started. Thermal cycling involved preincubation at $50^{\circ} \mathrm{C}$ for $2 \mathrm{~min}$, followed by denaturation for $10 \mathrm{~min}$ at $95^{\circ} \mathrm{C}, 40$ cycles were performed of denaturation for $15 \mathrm{sec}$ at $95^{\circ} \mathrm{C}$ and annealing/extension for $1 \mathrm{~min}$ at $60^{\circ} \mathrm{C}$ for $\mathrm{T}$ and $\mathrm{M}$ and $54^{\circ} \mathrm{C}$ for the P-GST-PCRs. Emission ranges of the fluorescent dye was measured real-time during PCR. To verify equal amounts of DNA subjected for amplification, the housekeeping gene hupo (human acidic ribosomal protein) was amplified for each sample using a predeveloped assay (PDAR No.4310879, ABI). Samples resulting in $\mathrm{C}_{t} \mathrm{~s}>30$ were qualified as positive. For all PCR-analyses, a no template negative control was included.

\section{Sequencing}

Specificity of probe-annealing for the P-polymorphisms was confirmed for representative samples by cycle sequencing (Big Dye Terminator v1.1, ABI, Weiterstadt, Germany). For that, samples were amplified with the same primers used before extended by standard M13 sequences. Then, amplification products were subjected for cycle sequencing reaction using M13 standard-primers for verification of amplification specificity (ABI PRISM 310 Genetic Analyzer, ABI) (data not shown).

\section{Statistical analysis}

Correlations between GST-status and CRSNP/CRSNP+, allergies, asthma and aspirin-intolerance were analysed using Fisher's exact test (data are shown in cross tables). To analyse correlations between asthma, allergy and aspirin-intolerance, we calculated correlation coefficients. As these diseases are slightly correlated, we calculated a new variable: 'concomitant diseases (CD)', which says whether an individual suffers from at least one of these diseases. We analysed associations of this new variable with GST-and CRS-status. For associations between all diseases the (corrected) $\Phi$-coefficient was calculated. All analyses were regarded as explorative, and the p-values of the corresponding tests are presented for descriptive reasons only. The results of these tests can therefore not be considered as significant at any level. Calculations were performed using the SPSS statistics software, version 15.0 (SPSS GmbH Software, Munich, Germany).

\section{RESULTS}

We analysed the GST-status of 170 patients (mean age 42 years). Of these, 118 samples were from patients with CRS; 49 were taken from patients without and 69 with nasal polyps. Fifty two samples of the inferior turbinate were taken from patients without CRS subjected for surgery because of nasal breathing impairment (turbinate reduction), acting as controls. Data concerning patients' allergies, asthmatics and aspirin intolerance were collected (for details please refer to the patients and methods section). Genotyping for the null 
Table 1. DNA-sequences of primers and probes used for PCR-analysis of GST-variants.

GST-T1 reverse: 5'-AGTCCTTGGCCTTCAGAATGA-3' GST-T1 Probe: 5'-6-FAMATGCTGCCCATCCCTGCCCTAMRA-3'

GST-M1 forward: 5'-CTTGGAGGAACTCCCTGAAAAG-3' GST-M1 reverse: 5'-TGGAACCTCCATAACACGTGA-3' GST-M1 Probe:

5'-6-FAMAAGCGGCCATGGTTTGCAGG-TAMRA-3' GST-P1 forward: 5'-CCTGGTGGACATGGTGAATG-3' GST-P1 reverse:

\section{5'-TGCTCACACCATAGTTGGTGTAGATGA-3'} GST-P1 Probe AL1: 5'-6-FAMTGCAAATACATCTCCCTTAMRA-3'

GST-P1 Probe AL2: 5'-6-FAMCTGCAAATACGTCTCCTAMRA-3'

genotypes of GSTM1 and GSTT1 revealed frequencies of $52.9 \%(\mathrm{n}=90)$ and $23.5 \%(\mathrm{n}=40)$, respectively. The frequency of the homozygous GSTP1 Val105 variant was $15.3 \%(\mathrm{n}=$ $26)$, of the homozygous Ile105 variant was $48.2 \%(n=82)$, and of the heterozygous Val/Ile variant was $36.5 \%(n=62)$, which is consistent with previously published data ${ }^{(3)}$.

We correlated the obtained genetic data to CRS, asthma, allergy, aspirin-intolerance and concomitant diseases (CD denotes allergy and/or asthma and/or aspirin intolerance). Sixty-four of our patients were suffering from allergies, 27 from asthma and 28 from aspirin-intolerance. Eighty-eight patients suffered from at least one of these. No statistical obvious correlation between any GST-variant or any combination of GST-variants (GSTT1 and GSTM1, data not shown) and CRS was found. A detailed analysis of aspirin-tolerant and intolerant patients, allergy, asthma and CD did not show an obvious association to any GST variant (Tables 2 and 3) (all p-values $>0.05$ ). In addition, we correlated CRS to allergies, asthma, aspirinintolerance and CD, as well as these diseases among each other (Table 4). The highest correlation was observed for asthma and aspirin intolerance (correlation coefficient, $\Phi=0.371$ ), which is in accordance with the well known clinical picture of the Samter triad, characterized by asthma, polyposis nasi and aspirin-intolerance. All other combinations correlated only at lower levels.

\section{DISCUSSION}

The Glutathion-S-Transferases are a group of detoxifying enzymes, mandatory to maintain cellular integrity. Under oxidative stress cellular molecules lose functionality by the reaction with reactive oxygen species (ROS) and the formation of aducts like lipid-peroxides, DNA-strand breaks and others. Studies on the lower respiratory tract gave evidence on the role of these enzymes in the development of inflammatory diseases. Romieu et al. investigated the severity of asthma in school children in Mexico City in relation to their GSTM1 status ${ }^{(17)}$. Children with functionally deficient GSTM1 showed a significantly reduced lung function (measured by FEF 25-75), when compared to children with the functional enzyme. Fryer et al. reported an association between GSTP1 genotypes and atopic airway disease ${ }^{(7)}$. The GSTP1 genotype was related to severity of airway dysfunction, as defined by BHR, which remained significant after correction for gender, age and atopy. Two

\begin{tabular}{|c|c|c|c|c|c|c|c|c|c|}
\hline & & controls & CRSNP- $^{-}$ & $\mathrm{CRSNP}^{+}$ & p-value & no CD & CD & p-value & total \\
\hline \multirow{2}{*}{$\begin{array}{c}\text { GST- } \\
\text { M1 }\end{array}$} & no & $\begin{array}{c}29 \\
32.2 \%\end{array}$ & $\begin{array}{c}26 \\
28.9 \%\end{array}$ & $\begin{array}{c}35 \\
28.9 \%\end{array}$ & \multirow{2}{*}{0.855} & $\begin{array}{c}49 \\
54.4 \%\end{array}$ & $\begin{array}{c}41 \\
45.6 \%\end{array}$ & \multirow{2}{*}{0.539} & 90 \\
\hline & yes & $\begin{array}{c}23 \\
28.8 \%\end{array}$ & $\begin{array}{c}23 \\
28.8 \%\end{array}$ & $\begin{array}{c}34 \\
42.5 \%\end{array}$ & & $\begin{array}{c}39 \\
48.8 \%\end{array}$ & $\begin{array}{c}41 \\
51.3 \%\end{array}$ & & 80 \\
\hline \multirow{2}{*}{$\begin{array}{c}\text { GST- } \\
\text { T1 }\end{array}$} & no & $\begin{array}{c}10 \\
25 \%\end{array}$ & $\begin{array}{c}13 \\
32.5 \%\end{array}$ & $\begin{array}{c}17 \\
42.5 \%\end{array}$ & \multirow{2}{*}{0.666} & $\begin{array}{c}18 \\
45 \%\end{array}$ & $\begin{array}{c}22 \\
55 \%\end{array}$ & \multirow{2}{*}{0.368} & 40 \\
\hline & yes & $\begin{array}{c}42 \\
32.3 \%\end{array}$ & $\begin{array}{c}36 \\
27.7 \%\end{array}$ & $\begin{array}{c}52 \\
40 \%\end{array}$ & & $\begin{array}{c}70 \\
53.8 \%\end{array}$ & $\begin{array}{c}60 \\
46.2 \%\end{array}$ & & 130 \\
\hline \multirow{3}{*}{$\begin{array}{c}\text { GST- } \\
\text { P1 }\end{array}$} & Ile/Ile & $\begin{array}{c}27 \\
32.9 \%\end{array}$ & $\begin{array}{c}28 \\
34.1 \%\end{array}$ & $\begin{array}{c}27 \\
32.9 \%\end{array}$ & \multirow{3}{*}{0.328} & $\begin{array}{c}44 \\
53.7 \%\end{array}$ & $\begin{array}{c}38 \\
46.3 \%\end{array}$ & \multirow{3}{*}{0.818} & 82 \\
\hline & Ile/Val & $\begin{array}{c}18 \\
29 \%\end{array}$ & $\begin{array}{c}16 \\
25.8 \%\end{array}$ & $\begin{array}{c}28 \\
45.2 \%\end{array}$ & & $\begin{array}{c}30 \\
48.4 \%\end{array}$ & $\begin{array}{c}32 \\
51.6 \%\end{array}$ & & 62 \\
\hline & Val/Val & $\begin{array}{c}7 \\
26.9 \%\end{array}$ & $\begin{array}{c}5 \\
19.2 \%\end{array}$ & $\begin{array}{c}14 \\
53.8 \%\end{array}$ & & $\begin{array}{c}14 \\
53.8 \%\end{array}$ & $\begin{array}{c}12 \\
46.2 \%\end{array}$ & & 26 \\
\hline \multicolumn{2}{|r|}{ tal } & $\begin{array}{c}52 \\
30.6 \%\end{array}$ & $\begin{array}{c}49 \\
28.8 \%\end{array}$ & $\begin{array}{c}69 \\
40.6 \%\end{array}$ & & $\begin{array}{c}88 \\
51.8 \%\end{array}$ & $\begin{array}{c}82 \\
48.2 \%\end{array}$ & & 170 \\
\hline
\end{tabular}

Table 2. Correlation between GST-polymorphisms and CRS without (CRSNP), with nasal polyps (CRSNP ${ }^{+}$), and concomitant diseases (CD). CD denotes allergy and/or asthma and/or aspirin intolerance. No correlation between any GST variant, CRSNP-, CRSNP+ ${ }^{+}$or CD was observed. 
putative mechanisms are suggested as to the association of respective polymorphisms and BHR or asthma: increased catalytic activity toward lipid hydroperoxides, resulting from the reaction with ROS, in GSTP1 Val105/Val105 individuals would decrease the ability of these ROS products to mobilize arachidonic acid. Thereby synthesis of proinflammatory eicosanoids might be reduced. Alternatively, decreased activity toward eicosanoids in GSTP1, Val105/Val105 individuals would also reduce synthesis of proinflammatory leukotriens (2). The potential role of GSTP1 polymorphisms with respect to the production of leukotriens and their bioavailability further enhances the significance of these mediators in nasal inflammatory disease. It might also be a key aspect in the obvious interindividual range of clinical phenotypes and could be crucial for future treatment protocols, taking into account the individual likelihood for good or poor treatment response. An investigation including about 1200 Californian school children detected a correlation between GSTP1 genotype and respiratory infections ${ }^{(3)}$ further supporting a role of these enzymes in the onset of inflammatory diseases of the respiratory tract. However, studies on the upper respiratory tract are rare. Two groups analyzed patients with nasal polyps and reported findings different to those from the lower airways. The authors found an association of GSTT1-null or GSTT1-null in combination with GSTM1-null and nasal polyps, respectively ${ }^{(15,16)}$. These results are not homogeneous, however, which might suggest that the onset of inflammatory diseases of the upper respiratory tract is linked to other GSTs than in the lower airways. To clarify this question, we now analysed the three GST-polymorphisms under discussion in nasal mucosa of control donors and patients with CRS from central Europe. Special emphasis was put on the question whether there is a correlation of GST-status and allergies or aspirin-intolerance. However, we found no obvious association of GST polymorphisms and CRS, polyp formation, aspirin-intolerance or any other analysed parameter. Our data give no evidence for the involvement of the GSTs in upper airway diseases. This is not in line with the two former studies reporting an association of GST polymorphisms and nasal polyp formation. However, as these two studies were performed exclusively in Turkish patients, ethnic differences might be of relevance. Ethnical differences of polymorphisms have been described earlier by Paiva et al., who reported about polymorphisms of another GST (GSTO2), detected in Europeans and Chilean Indians with significantly different allelic frequencies ${ }^{(18)}$.

In summary, our results do not suggest that inflammatory diseases of the upper respiratory tract occur on the same genetic background as those of the lower respiratory tract as far as GST-polymorphisms are concerned. Moreover, our data do not indicate a genetic predisposition considering the individual GST-status for the susceptibility developing chronic rhinosinusitis and nasal polyps in German adults. Other environmental and/or genetic factors might predispose to the onset of inflammation of the upper airways.

\begin{tabular}{|c|c|c|c|c|c|c|c|c|c|c|c|}
\hline & & \multicolumn{3}{|c|}{ asthma } & \multicolumn{3}{|c|}{ allergies } & \multicolumn{3}{|c|}{ aspirin-intolerance } & \multirow{2}{*}{ total } \\
\hline & & no & yes & $\mathrm{p}$-value & no & yes & $\mathrm{p}$-value & no & yes & $\mathrm{p}$-value & \\
\hline \multirow{2}{*}{$\begin{array}{l}\text { GST- } \\
\text { M1 }\end{array}$} & no & $\begin{array}{c}78 \\
86.7 \%\end{array}$ & $\begin{array}{c}12 \\
13.3 \%\end{array}$ & \multirow{2}{*}{0.402} & $\begin{array}{c}58 \\
64.4 \%\end{array}$ & $\begin{array}{c}32 \\
35.6 \%\end{array}$ & \multirow{2}{*}{0.635} & $\begin{array}{c}77 \\
85.6 \%\end{array}$ & $\begin{array}{c}13 \\
14.4 \%\end{array}$ & \multirow{2}{*}{0.536} & 90 \\
\hline & yes & $\begin{array}{c}65 \\
81.3 \%\end{array}$ & $\begin{array}{c}15 \\
18.8 \%\end{array}$ & & $\begin{array}{c}48 \\
60 \%\end{array}$ & $\begin{array}{c}32 \\
40 \%\end{array}$ & & $\begin{array}{c}65 \\
81.3 \%\end{array}$ & $\begin{array}{c}15 \\
18.8 \%\end{array}$ & & 80 \\
\hline \multirow{2}{*}{$\begin{array}{c}\text { GST- } \\
\text { T1 }\end{array}$} & no & $\begin{array}{c}34 \\
85 \%\end{array}$ & $\begin{array}{c}6 \\
15 \%\end{array}$ & \multirow{2}{*}{1} & $\begin{array}{c}20 \\
50 \%\end{array}$ & $\begin{array}{c}20 \\
50 \%\end{array}$ & \multirow{2}{*}{0.092} & $\begin{array}{c}33 \\
82.5 \%\end{array}$ & $\begin{array}{c}7 \\
17.5 \%\end{array}$ & \multirow{2}{*}{0.811} & 40 \\
\hline & yes & $\begin{array}{c}109 \\
83.8 \%\end{array}$ & $\begin{array}{c}21 \\
16.2 \%\end{array}$ & & $\begin{array}{c}86 \\
66.2 \%\end{array}$ & $\begin{array}{c}44 \\
33.8 \%\end{array}$ & & $\begin{array}{c}109 \\
83.8 \%\end{array}$ & $\begin{array}{c}21 \\
16.2 \%\end{array}$ & & 130 \\
\hline \multirow{3}{*}{$\begin{array}{l}\text { GST- } \\
\text { P1 }\end{array}$} & Ile/Ile & $\begin{array}{c}71 \\
86.6 \%\end{array}$ & $\begin{array}{c}11 \\
13.4 \%\end{array}$ & \multirow{3}{*}{0.658} & $\begin{array}{c}53 \\
64.6 \%\end{array}$ & $\begin{array}{c}29 \\
35.4 \%\end{array}$ & \multirow{3}{*}{0.681} & $\begin{array}{c}70 \\
85.4 \%\end{array}$ & $\begin{array}{c}12 \\
14.6 \%\end{array}$ & \multirow{3}{*}{0.566} & 82 \\
\hline & Ile/Val & $\begin{array}{c}51 \\
82.3 \%\end{array}$ & $\begin{array}{c}11 \\
17.7 \%\end{array}$ & & $\begin{array}{c}36 \\
58.1 \%\end{array}$ & $\begin{array}{c}26 \\
41.9 \%\end{array}$ & & $\begin{array}{c}52 \\
83.9 \%\end{array}$ & $\begin{array}{c}10 \\
16.1 \%\end{array}$ & & 62 \\
\hline & $\mathrm{Val} / \mathrm{Val}$ & $\begin{array}{c}21 \\
80.8 \%\end{array}$ & $\begin{array}{c}5 \\
19.2 \%\end{array}$ & & $\begin{array}{c}17 \\
65.4 \%\end{array}$ & $\begin{array}{c}9 \\
34.6 \%\end{array}$ & & $\begin{array}{c}20 \\
76.9 \%\end{array}$ & $\begin{array}{c}6 \\
23.1 \%\end{array}$ & & 26 \\
\hline \multicolumn{2}{|c|}{ total } & $\begin{array}{c}143 \\
84.1 \%\end{array}$ & $\begin{array}{c}27 \\
15.9 \%\end{array}$ & & $\begin{array}{c}106 \\
62.4 \%\end{array}$ & $\begin{array}{c}64 \\
37.6 \%\end{array}$ & & $\begin{array}{c}142 \\
83.5 \%\end{array}$ & $\begin{array}{c}28 \\
16.5 \%\end{array}$ & & 170 \\
\hline
\end{tabular}

Table 3. Correlation between GST-polymorphisms and asthma, allergies and aspirin intolerance. No correlation between any GST variant and asthma, allergies or aspirin intolerance was observed. 


\begin{tabular}{|l|c|c|c|c|}
\hline & allergy & asthma & $\begin{array}{c}\text { aspirin- } \\
\text { intolerance }\end{array}$ & $\begin{array}{c}\text { concomitant } \\
\text { diseases (CD) }\end{array}$ \\
\hline CRS & 0.021 & 0.195 & 0.328 & 0.141 \\
\hline allergy & - & 0.227 & 0.048 & - \\
\hline asthma & - & - & 0.371 & - \\
\hline
\end{tabular}

Table 4. Correlation coefficients $[\Phi]$ for diseases. Correlation coefficients were corrected. The highest correlation was observed for asthma and aspirin intolerance.

\section{ACKNOWLEDGMENTS}

Data will be included in part in the doctoral theses of M. Amro and N. Best.

\section{AUTHOR CONTRIBUTION}

$\mathrm{KF}$ : writing, patient coordination, gathering tissue samples, data analysis; NB: laboratory work, data analysis; MA: laboratory work, data analysis; KI: data analysis; JG: supervision of clinical analysis, gathering tissue samples, writing; WM: supervision; JB: coordination of laboratory work, supervision, data analysis and writing.

\section{CONFLICT OF INTEREST}

No conflicts to declare.

\section{REFERENCES}

1. Hayes JD, Strange RC. Potential contribution of the glutathione S-transferase supergene family to resistance to oxidative stress. Free Radic Res 1995; 22: 193-207.

2. Hayes JD, Strange RC. Glutathione S-Transferase Polymorphisms and Their Biological Consequences. Pharmacology 2000; 61: 154166

3. Gilliland FD, Rappaport EB, Berhane K, et al. Effects of Glutathione S-Transferase P1, M1, and T1 on Acute Respiratory Illness in School Children. Am J Respir Crit Care Med 2002; 166: 346-351.

4. Tamer L, Calikoglu M, Ates NA, et al. Glutathione-S-transferase gene polymorphisms (GSTT1, GSTM1, GSTP1) as increased risk factors for asthma. Respirology 2004; 9: 493-498.

5. Hanene C, Jihene L, Jamel A, Kamel H, Agnes H. Association of GST genes polymorphisms with asthma in Tunisian children. Mediators Inflamm 2007; 2007: 19564.

6. Kamada F, Mashimo $\mathrm{Y}$, Inoue $\mathrm{H}$, et al. The GSTP1 gene is a susceptibility gene for childhood asthma and the GSTM1 gene is a modifier of the GSTP1 gene. Int Arch Allergy Immunol 2007; 144: 275-286.

7. Fryer AA, Bianco A, Hepple M, Jones PW, Strange RC, Spiteri ma. Polymorphism at the Glutathione S-transferase GSTP1 Locus. A New Marker for Bronchial Hyperresponsiveness and Asthma. Am J Respir Crit Care Med 2000; 161: 1437-1442.
8. David GL, Romieu I, Sienra-Monge JJ, et al. Nicotinamide Adenine Dinucleotide (Phosphate) Reduced:Quinone Oxidoreductase and Glutathione S-Transferase M1 Polymorphisms and Childhood Asthma. Am J Respir Crit Care Med 2003; 168: 1199-1204.

9. Imboden $\mathrm{M}$, Rochat $\mathrm{T}$, Brutsche $\mathrm{M}$, et al. Glutathione S-transferase genotype increases risk of progression from bronchial hyperresponsiveness to asthma in adults. Thorax 2008; 63 : 322-328.

10. Minelli C, Granell R, Newson R, et al. Glutathione-S-transferase genes and asthma phenotypes: a Human Genome Epidemiology (HuGE) systematic review and meta-analysis including unpublished data. Int J Epidemiol 2010; 39: 539-562.

11. Feuillet-Fieux MN, Nguyen-Khoa T, Loriot MA, et al. Glutathione S-transferases related to P. aeruginosa lung infection in cystic fibrosis children: preliminary study. Clin Biochem 2009; 42: $57-63$.

12. Oretti C, Marino S, Mosca F, et al. Glutathione-S-transferase-P1 I105V polymorphism and response to antenatal betamethasone in the prevention of respiratory distress syndrome. Eur J Clin Pharmacol 2009; 65: 483-491.

13. Fokkens W, Lund V, Mullol J. European position paper on rhinosinusitis and nasal polyps 2007. Rhinology. Suppl 20; 2007: $1-136$.

14. Ponikau JU, Sherris DA, Kephart GM, et al. Features of airway remodeling and eosinophilic inflammation in chronic rhinosinusitis: Is the histopathology similar to asthma? J Allergy Clin Immunol 2003; 112: 877-882.

15. Ozcan C, Tamer L, Ates NA, Gorur K. The glutathione-S-transferase gene polymorphisms (Gstt1, Gstm1, and Gstp1) in patients with non-allergic nasal polyposis. Eur Arch Otorhinolaryngol 2010; 267: 227-232.

16. Arbag H, Cora T, Acar H, Ozturk K, Sari F, Ulusoy B. Lack of association between the glutathione-s-transferase genes (GSTT1 and GSTM1) and nasal polyposis. Rhinology 2006; 44: 14-18.

17. Romieu I, Sienra-Monge JJ, Ramirez-Aguilar M, et al. Genetic polymorphism of GSTM1 and antioxidant supplementation influence lung function in relation to ozone exposure in asthmatic children in Mexico City. Thorax 2004; 59: 8-10.

18. Paiva L, Hernández A, Martínez V, Creus A, Quinteros D, Marcos R. Association between GSTO2 polymorphism and the urinary arsenic profile in copper industry workers. Environ Res; 110: 463-468.
Kai Fruth, MD

Department of Otorhinolaryngology, Head and Neck Surgery

University Medical Center of the Johannes Gutenberg

University Mainz

Langenbeckstrasse 155101

Mainz

Germany

Tel: +49-6131 177361

Fax: +49-6131 176637

E-mail: fruth@hno.klinik.uni-mainz. de 